\title{
Numerical Simulation and Optimization of Gas-Solid Turbulence Flow in a Precalciner
}

\author{
S. X. Mei*, J. L. Xie
}

Key Laboratory for Silicate Materials Science and Engineering, Wuhan University of Technology, Wuhan 430070, China

Email: msx0303@163.com

\begin{abstract}
Precalciner is a key equipment in kiln system of cement industry. To enhance precacination degree and reduce energy consumption, it is important to design high-powered precalciners with not only a good solid dispersing condition, but also optimum performance characteristics such as low pressure drop, high solid residence-time, and high residence-time ratio between solid and gas.To optimize the gas-solid flow field of an actual precalciner, numerical simulation was carried out using operationalbased boundary conditions. In Euler coordinate system the gas phase is expressed with $\mathrm{k}-\varepsilon$ model, in Lagrange coordinate system the solid phase is expressed with Discrete Phase Model (DPM), and the random effects of turbulence on the particle dispersion is accounted for with Discrete Random Walk (DRW) model.

The predicted gas velocity field shows that the gas flow rises up spirally, which agrees well with what observed on the actual running precalciner. The calculated raw meal concentration distributions are consistent with the actual conditions, indicating a good dispersing condition of raw meal. By changing the initial tertiary air velocity but fixing the initial flue gas velocity-and vice versa-the predicted results were compared. With the fixed initial flue gas velocity, the tertiary air velocity range between $25 \mathrm{~m} / \mathrm{s}$ and $30 \mathrm{~m} / \mathrm{s}$ is suggested, with the the fixed initial tertiary air velocity, it is optimum when the flue gas velocity is between $25 \mathrm{~m} / \mathrm{s}$ and $35 \mathrm{~m} / \mathrm{s}$.
\end{abstract}
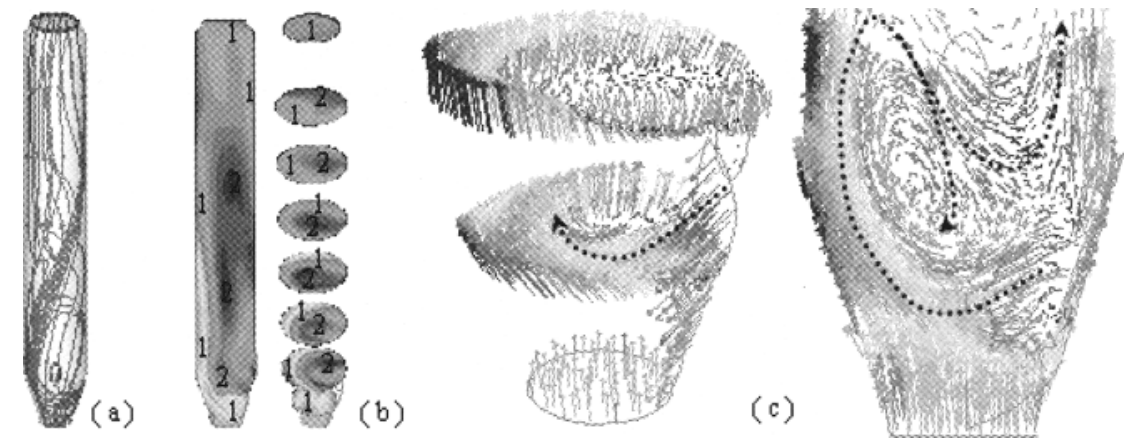

Figure: Gas flow field: (a) streamlines; (b) velocity contours; (c) velocity vector.

\section{REFERENCES}

1. Hu ZJ, Lu JD, Huang L, Wang SJ. Numerical simulation study on gas-particles two-phase flow in pre-calciner. Communications in Nonlinear Science and Numerical Simulation, 2006; 11: 440-451 